Please note that all letters must be typed. Priority will be given to those that are less than $\mathbf{5 0 0}$ words long. All authors must sign the letter, which may be shortened or edited for reasons of space or clarity. All letters received are acknowledged.

\section{Whistle blowing}

Sir-- Messrs McIntyre and Mossey (BDJ 2001; 190: 522-523) remind us that orthodontic treatment should be based on internationally accepted gold standards and randomized controlled trials when possible.'

I would certainly agree. Therefore, how can we all have different viewpoints? It can only be the quality of the evidence or the logic applied to it.

Unfortunately, the quality of most orthodontic research is poor. This is not my opinion, just ask the evidence based experts (BDJ 2001; 190: 226). Messrs McIntyre and Mossey are equally critical of unproven techniques but the existing evidence would not give me the confidence that any orthodontic technique is assuredly reliable, permanent and without adverse side effects. In these circumstances a prudent clinician should perhaps refrain from providing treatment at all.

Orthodontists are not always aware of the cynicism felt by older dentists whose practices contain many long-term orthodontic failures.

As far as the logic is concerned, I feel confident that the 'opinion' I expressed on the 'Dispatches' programme, ' $20 \%$ of faces are noticeably damaged and a further 30\% slightly damaged' is true and I see no reason to doubt it. There is overwhelming evidence to show that orthodontic treatment lengthens faces more than untreated controls and that longer faces are less attractive. What other logical conclusion is possible?

We must find consensus on these issues, rather than sheltering behind our emotional barriers slinging references at each other. There is room for many opinions but there can only be one truth and we are more likely to find that from the basic sciences than from the current clinical evidence.

I have repeatedly asked the specialty to arrange a friendly debate during which everyone is given the chance to put their point for an independent panel to review.

Might the BDA or some other body be prepared to sponsor such a meeting? Without it the bickering will continue, to everyone's disadvantage.

\section{J. Mew}

\section{Heathfield}

The authors P. A. Mossey and G. T. McIntyre respond:

John Mew is quite right to state that the differences in the unfortunately polarised concepts of the effects of orthodontic treatment could result from 'the quality of the evidence or the logic applied to it.'

Of course, in orthodontic interventions, as in all areas of medicine and dentistry, the 'quality' issue relates to the fact that there is good evidence and bad evidence.

Furthermore, the 'logic' issue is closely related to how the evidence is viewed or interpreted.

Evidence such as case reports, case series or case-control same-sexed twin studies are considered by the scientific community to be near the bottom of the hierarchy of evidence levels, ${ }^{1}$ yet they continue to be used in isolation to support claims and opinions. Conversely, high quality evidence, for example from randomised controlled trials (RCTs) can be ignored.

John Mew might well be right in some of his claims regarding long-term outcome of orthodontic intervention, but the evidence to support his claims is simply not available, and it is generally true to say that to date there is precious little high quality evidence in the field of orthodontics.

Few clinicians or researchers would disagree with Mr Mew that our efforts should be towards seeking the 'truth' and we need to know how to approach this problem. In the field of orthodontics, the reason for success or failure may in some instances, be sought through basic science research, but the 'truth' in the effectiveness of clinical interventions will only be provided by the clinical RCT. We are therefore faced with the inescapable conclusion that clinical research is absolutely essential in this field and well-designed RCTs over long time periods are necessary.

John Mew calls for a forum for discussion and friendly debate. In the absence of 'evidence' we think this debate would be inconclusive, but if it would identify gaps and stimulate ideas for future research it would be useful. A suitable forum, we would suggest, already exists in the form of the British Orthodontic Conference, and while those who present scientific evidence are particularly welcome, this forum has always welcomed input from all shades of opinion.

1. Richards D, Lawrence A. Evidence based dentistry. Br Dent J 1995; 179: 270-273

\section{GDC election}

Sir, - Having been returned in the recent GDC election I am all too aware of the responsibility placed upon me at this time of rapid change for our profession. I will do my best to achieve a fair outcome for both practitioners and PCDs as the Council enters uncharted waters.

I shall continue to be available both at home and in my practice should any practitioner wish to discuss any of the various topics confronting the profession or simply to find out what is going on.

I would very much like to thank my colleagues for their enthusiastic support.

\section{Pike}

\section{Sudbury}

Sir,- I I would like to take this opportunity to thank those who voted for me in the GDC elections, where I came to within six places of a seat on the Council. I am most grateful for this level of support and trust. Many thanks to you all.

\section{K. I. Wilson}

\section{Chesterfield}

\section{Tracing students}

Sir,- We have many graduates from Khyber College of Dentistry, Pakistan, working and studying in the UK, and we are finding it difficult to trace old students from 1964 onwards.

We have therefore formed KCD Alumni and our graduates are requested to submit their address at kcd@pakistanmail.com, or visit http://kcd.8m.net

\section{G. Babar}

Pakistan

\section{Community care}

Sir,- I was interested to read Geoff Taylor's letter titled 'Community Care' (BDJ 2001; 190: 633) and would agree wholeheartedly that compelling dentists to undertake treatment which they do not feel competent to do, would be totally contrary to the requirements of clinical governance.

However, I did not recognise the picture of 1,000 community dentists who had not treated an adult for many years. This does not describe the community dental service that I and many colleagues know and work in today, indeed, we are at a loss to know where Geoff has found these 1,000 dentists. Informal soundings of clinical director colleagues suggests that most dentists working in their services are treating a variety of priority groups, including many adults. I continue to be amazed by the complex and challenging needs of many of the adults treated by the dentists working in my team and also by the range and complexity of the dentistry provided for them.

One of the strands of clinical governance is promotion of evidence based clinical interventions. Should not the letters section of the BDJ be similarly evidence based?

\section{J. Clarke}

\section{Hallow}

Sir,- I write in response to the letter by G. Taylor 'Community Care' (BDJ 2001; 190: 
633). While I agree with the majority of this letter, the final paragraph cannot pass without comment.

1,000 clinical dental officers in the CDS who have not treated an adult for many years? I challenge G. Taylor to produce the evidence for this assertion. I believe that the majority of CDS dental practitioners do indeed provide a specialist complementary service for individuals who have a special requirement for dentistry.

These people include those with physical disabilities, mental health problems, learning disabilities and those who are medically or virally compromised. Some of these individuals are children and some are adults, some elderly adults. In my own service, 70 per cent of our contacts are adults and readers may be surprised to learn that we offer the full range of dental treatment to those adults. This will include molar endodontics, crowns, veneers; in fact, whatever is appropriate for that patient.

I take extreme exception to the assumption explicit in G. Taylor's letter that most community dental practitioners treat solely children - they do not. It is just this sort of ill-informed comment that makes establishment of a specialty in special care dentistry such an up-hill battle.

The critical issue for CDS is recruitment, we do not wish to sacrifice our special need role for general NHS dentistry. However, many services are very happy to expand to embrace general dentistry, providing treatment for ordinary people who are having difficulty accessing NHS care.

\section{J. A. Brooks \\ Clinical Director, Community and \\ Personal Dental Services, South Warwickshire}

\section{Professional flexibility}

Sir,- I would like to reassure Mr Strachan (BDJ 2001; 190:578) that since the arrival of my son, delightful and accommodating as he is (as babies go), I, too, no longer have any flexibility. I am looking forward to returning to work (as a locum consultant orthodontist, part time of course) so that I can provide human care on a strict appointment-only basis.

\section{Nightingale}

\section{London}

\section{NHS proposals for change}

Sir,- I I was interested to read the letter entitled 'NHS plan-proposal for new approach' in the last edition. ${ }^{1}$ I agree wholeheartedly with the sentiments expressed and would like to add another specialty to the debate, not already mentioned in the letter.
Oral medicine is a specialty (along with maxillofacial surgery) which requires its trainees to possess both medical and dental undergraduate degrees. Again, the medical degree of up to five years is self-funded. In addition, however, since most consultant posts are actually appointed at senior lecturer level in the university system, the possession of a $\mathrm{PhD}$ is almost mandatory. Not only does this prolong the period of training prior to appointment to a consultant post by at least a further three years, but funding for $\mathrm{PhD}$ studies is by no means certain, and can be difficult to obtain.

The possible prohibition for seven years after consultant appointment, before entertaining any sort of private practice would seem to be a step too far and the whole concept of a period of restricted practice after consultant appointment in any specialty should be resisted. If this seems a debate remote from colleagues in general practice, does it make any more sense than, say, a proposition that post VT dental practice should be limited to only NHS treatments for seven years?

\section{P. A. Atkin \\ London}

1. Dixon M, Derwent S K. NHS plan-proposal for new approach. BDJ 2001; 191: 2

\section{Dental tape - a cautionary tale}

Sir-— Since the advent of PTFE dental tape (the most popular brand of which seems to be 'Gore-Tex', although there are others available), I have been an enthusiastic advocate, due to its ease of use and disinclination to snag or fray.

I would, however, be grateful to be allowed to advise those of your readers who, like myself, practice in rural areas where 'septic tank' drainage is still fairly common, that due to its non-biodegradeable nature and apparent lipophilic properties, PTFE floss should not be disposed of into the waste water system. I have just spent an entire Saturday afternoon dislodging a 4 inch diameter ball of PTFE floss and solidified kitchen fat from the gas trap of my own septic tank, where it had caused total obstruction. On my list of preferred weekend activities, I can assure you the above procedure ranks close to bottom!

\section{J. Clague-Moore \\ Isle of Man}

\section{Self-evaluation skills in dentistry}

Sir, - Congratulations on your article 'Gathering information 2: methods of assessment' (BDJ 2001; 191: 11-18).

Certainly for continuing professional development (CPD) to be successful it is necessary to be aware of one's weaknesses and to continually evaluate one's skills to identify areas most in need of improvement and relevant to our practice. The self evaluation questionnaires and interviews described offer practical methods of achieving this.

The claim that self-assessment skills, coupled with the ability to self-educate are required to ensure the continued competence of the physician ${ }^{1}$ can be equally applied to dentistry. However, studies have shown that weaker performers are more likely to overrate themselves both generally and within medicine and dentistry. ${ }^{1,2,3}$ To ensure the effectiveness of CPD we need accurate self-evaluation and assessment, yet there is surprisingly little teaching of these skills at any stage of dental training.

Could I suggest that self-evaluation and assessment is a fundamental skill and should be introduced into both the undergraduate and postgraduate curriculum? Familiarity with the process should improve the validity of one's evaluation, motivate learning and ensure more effective CPD.

\section{A. W. Evans}

\section{London}

1. Woolliscroft J O, TenHaken J, Smith J, Calhoun J G. Medical students' clinical self-assessments: Comparisons with external measures of performance and the students' self-assessments of overall performance and effort. Acad Med 1993; 68: 285-294.

2. Boud D, Falchikov N. What does research tell us about self-assessment? In Boud D.

Enhancing learning through self-assessment. London. Kogan Page 1999.

3. Evans A W, Aghabeigi B, Leeson R, O'Sullivan $\mathrm{C}$, Eliahoo J. Are we really as good as we think we are? Annals RCS.

\section{Mission impossible}

Sir, - With respect, I believe the Editor has ignored his own mission statement '...to inform its readers of ideas, opinions, developments and key issues in dentistry $(B D J$ 2001; 191: 27-28). This particular issue of the $B D J$ deserves the same fate as the unfortunate toothbrush described by Kumar in his irrelevant article.

\section{Wallis}

Epping

Please send your letters to:

$$
\begin{aligned}
& \text { The Editor } \\
& \text { British Dental Journal } \\
& 64 \text { Wimpole Street } \\
& \text { London } \\
& \text { W1M 8AL }
\end{aligned}
$$

